Supplement of Solid Earth, 12, 2351-2368, 2021

https://doi.org/10.5194/se-12-2351-2021-supplement

(c) Author(s) 2021. CC BY 4.0 License.

(c) (i)

solit tart EG EGU

Supplement of

\title{
The effect of 2020 COVID-19 lockdown measures on seismic noise recorded in Romania
}

\author{
Bogdan Grecu et al. \\ Correspondence to: Bogdan Grecu (bgrecu@infp.ro)
}

The copyright of individual parts of the supplement might differ from the article licence. 


\section{Contents of this file:}

Figure S1: Comparison of long-term evolution of seismic noise at BTMR station in Bucharest estimated in the frequency band of 2-8 Hz from a) velocity data and b) acceleration data.

Figure S2: Comparison of seismic noise and wind data at station MLR (Muntele Rosu). (a) Long-term evolution of seismic noise. The two vertical lines mark the May 01 - 10 interval for which the analysis was performed. (b) Spectrogram computed in the frequency band 4-14 Hz. (c) Representation of the wind speed data. Note a good correlation between the noise peak observed in the selected window (a), the increase of the noise power in the spectrogram between May 06 and May 08, 2020 (b) and the significant increase of the wind speed for the same interval (c).

Figure S3: Lockdown effects shown on 24-hour clock plots at the station PMGR located in the park in Mogosoaia city.

Figure S4: Changes in DRMS at stations CTISU and BTMR compared to Google (a) and Apple's (b) mobility data.

Table S1: An overview of the lockdown measures implemented in Romania.

Figure S1 is to support the Data and method section of the manuscript, to illustrate the similar shape of DRMS computed using velocity and accelerometer recordings.

Figure S2 is to support the Results section of the manuscript, to illustrate the long-term evolution of DRMS at the MLR station in connection with wind speed variations.

Figure S3 is to support the Discussion section of the manuscript to better illustrate the influence of the movement of people on the seismic noise variation in the vicinity of a seismic station.

Figure S4 is to support the Discussion section of the manuscript to better illustrate the match between the variation in seismic noise and data mobility's trends.

Table 1 is to support the Introduction section of the manuscript to present an overview of the lockdown measures implemented in Romania. 

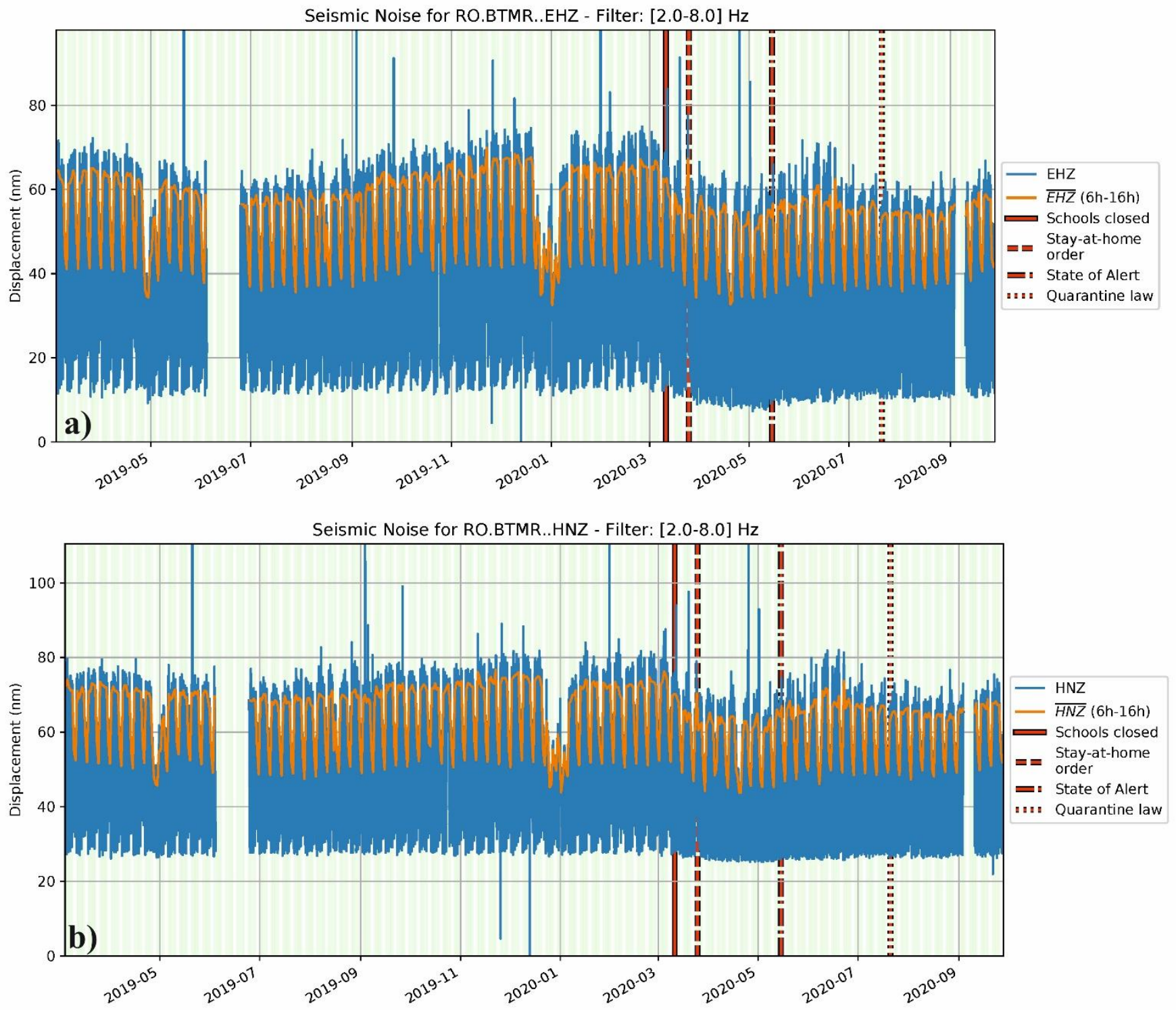

Figure S1: Comparison of long-term evolution of seismic noise at BTMR station in Bucharest estimated in the frequency band of 2-8 Hz from a) velocity data and b) acceleration data. 
a)
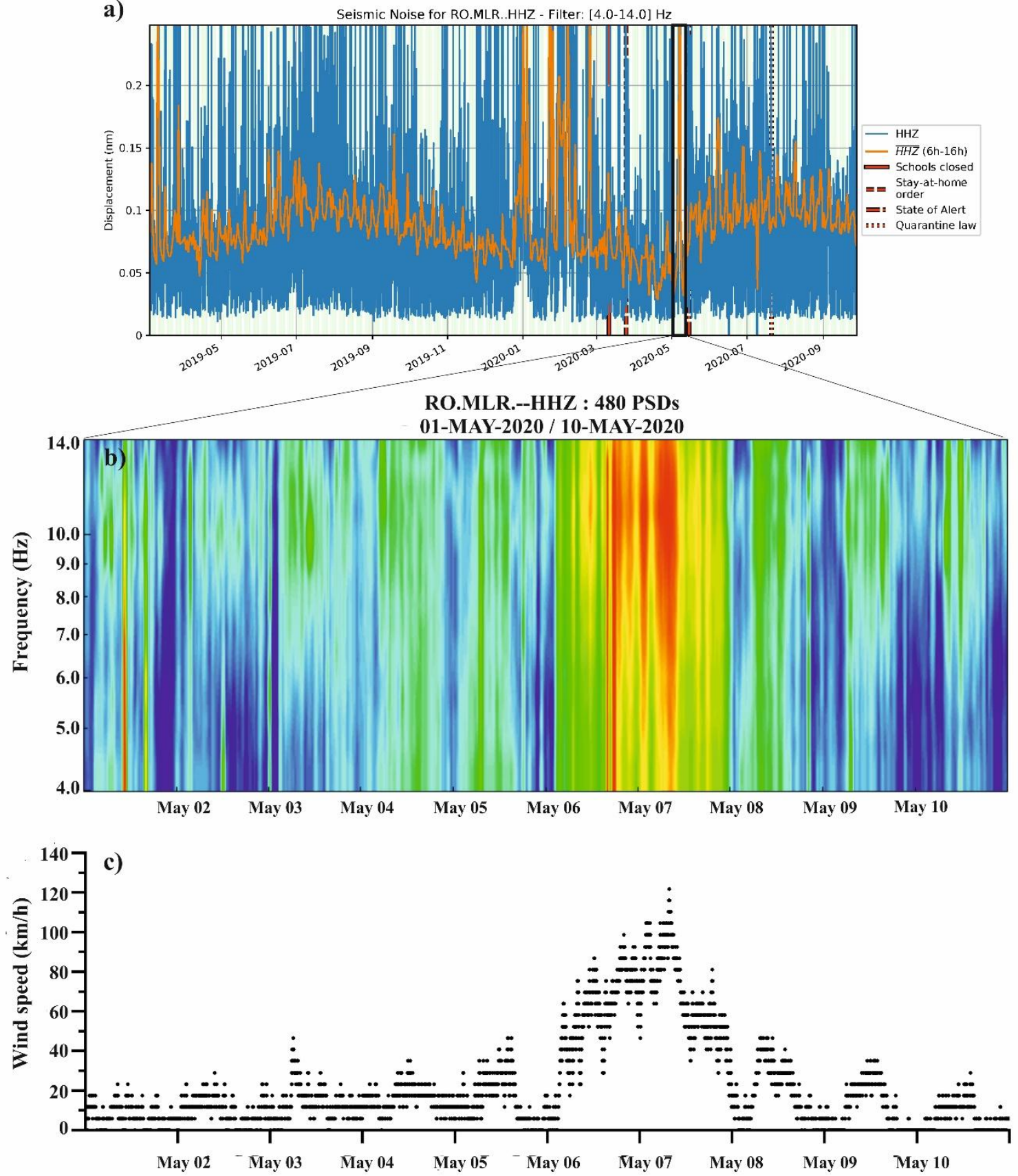

Figure S2: Comparison of seismic noise and wind data at station MLR (Muntele Rosu). (a) Long-term evolution of seismic noise. The two vertical lines mark the May 01 - 10 interval for which the analysis was performed. (b) Spectrogram computed in the frequency band 4-14 Hz. (c) Representation of the wind speed data. Note a good correlation between the noise peak observed in the selected window (a), the increase of the noise power in the spectrogram between May 06 and May 08, 2020 (b) and the significant increase of the wind speed for the same interval (c). 


\section{Day/Hour Median Noise levels \\ Station RO.PMGR..HNZ - [15.0-25.0] Hz}
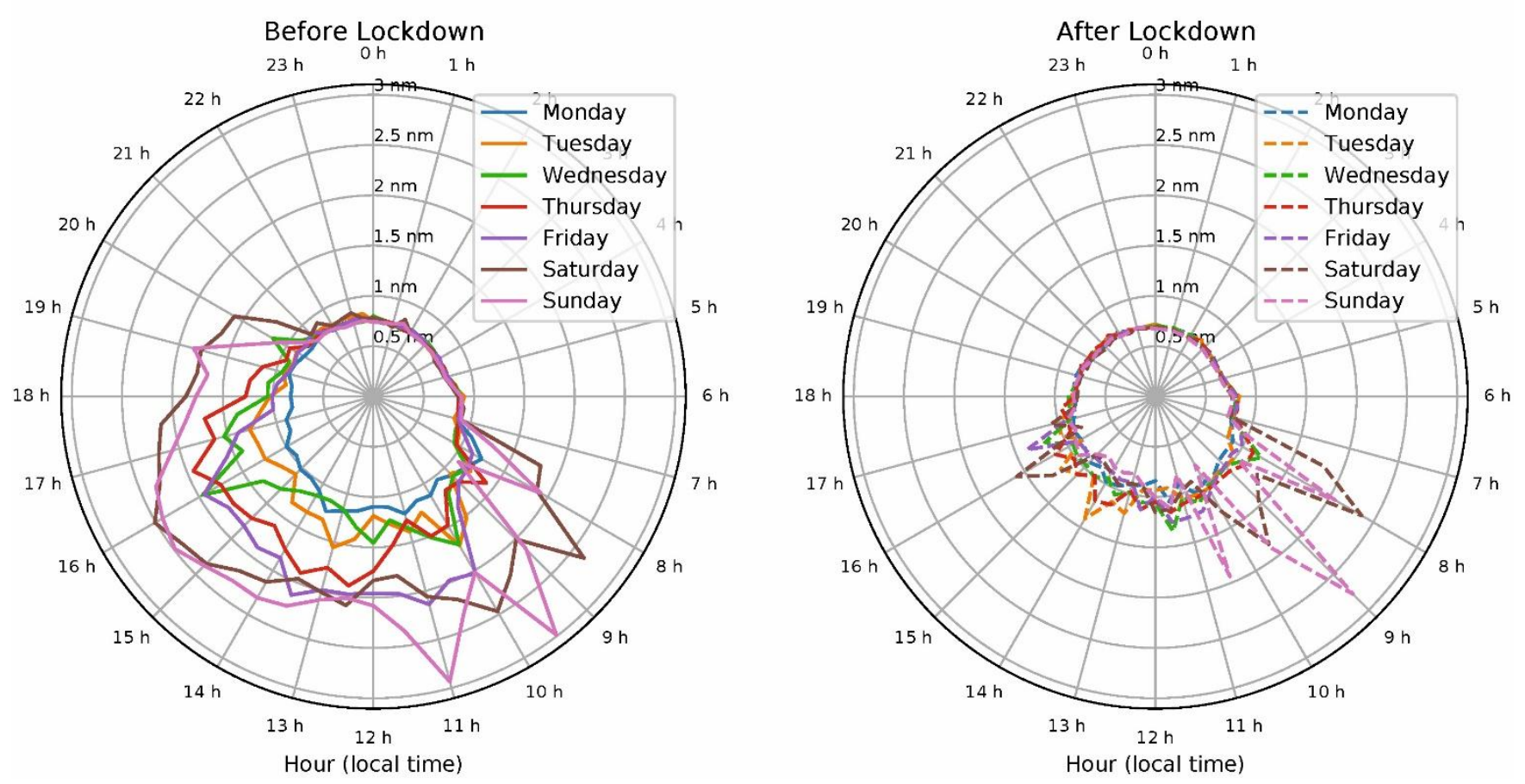

Figure S3: Lockdown effects shown on 24-hour clock plots at the station PMGR located in the park in Mogosoaia city. 


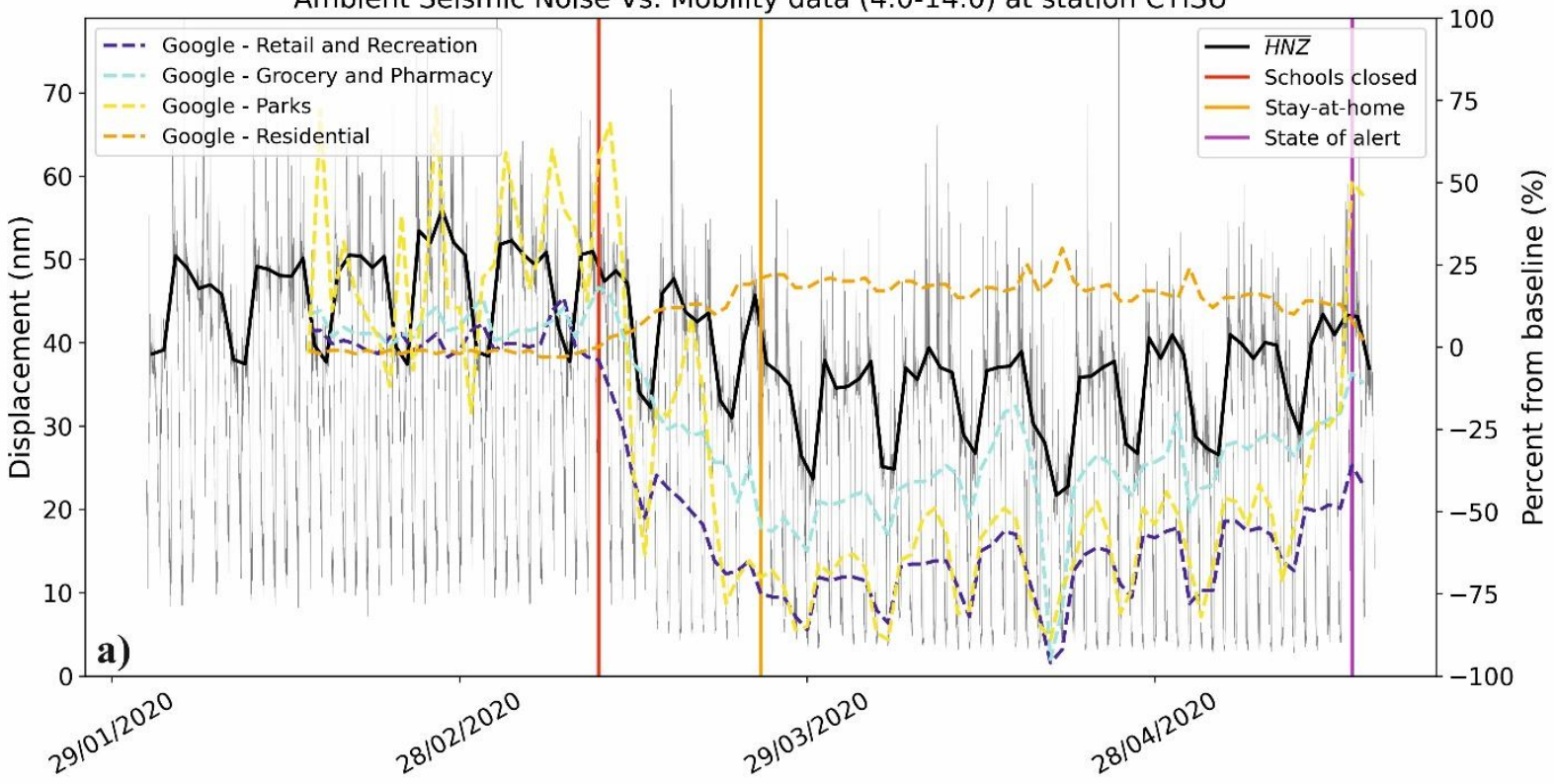

Ambient Seismic Noise Vs. Mobility data (15.0-25.0) at station BTMR

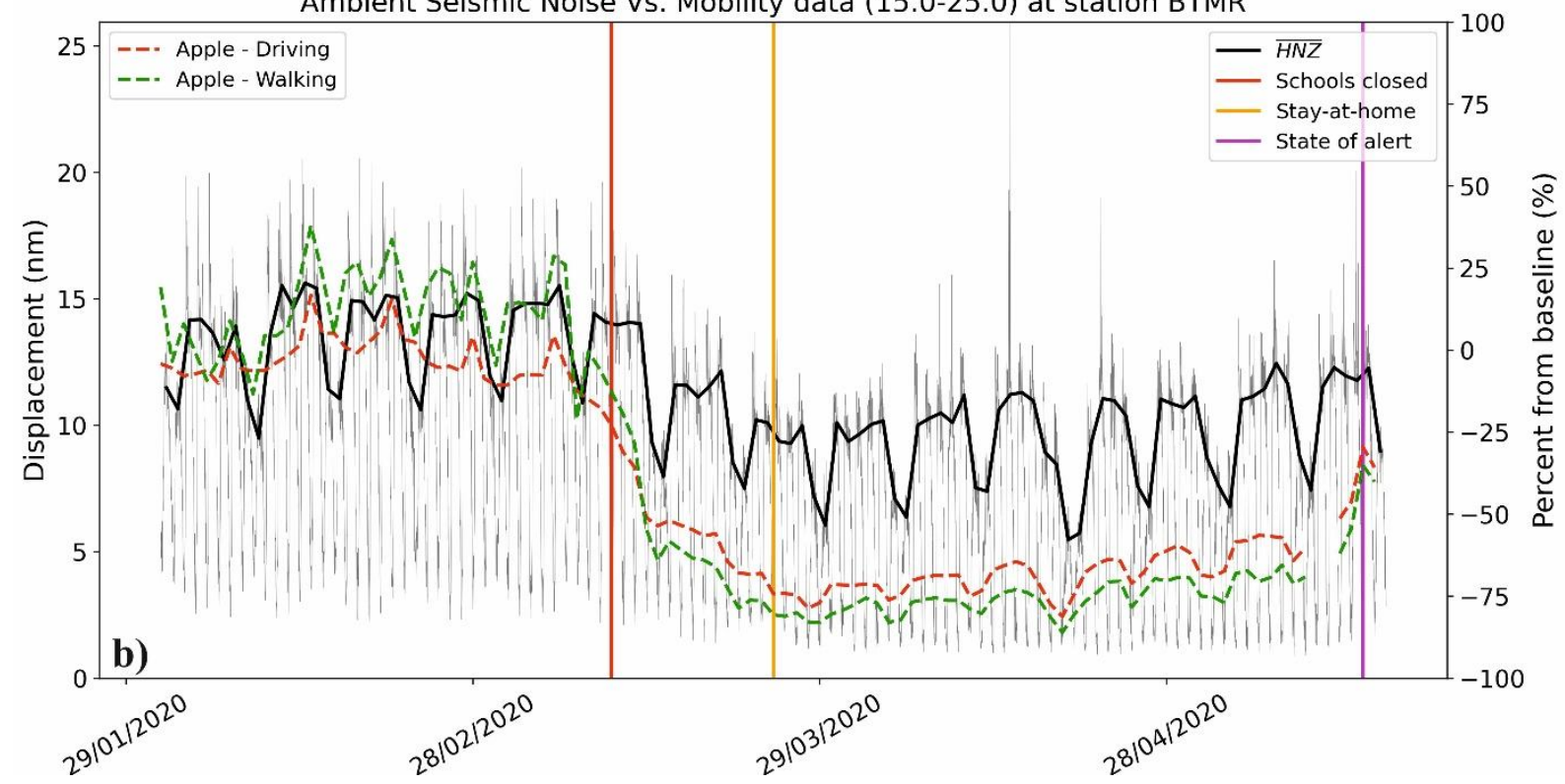

Figure S1: Changes in DRMS at stations CTISU and BTMR compared to Google (a) and Apple's (b) mobility data. 
Table S1: An overview of the lockdown measures implemented in Romania

\begin{tabular}{|c|c|c|}
\hline DATE & ACTION & OBSERVATIONS \\
\hline February 26, 2020 & $\begin{array}{l}\text { The first case of COVID-19 was } \\
\text { reported in Romania. }\end{array}$ & \\
\hline March 11, 2020 & All schools in Romania were closed. & $\begin{array}{l}\text { The World Health Organization (WHO) } \\
\text { declared the novel coronavirus (COVID-19) } \\
\text { outbreak a global pandemic. }\end{array}$ \\
\hline March 16, 2020 & The state of emergency was declared. & \\
\hline March 17, 2020 & The first military order was issued. & $\begin{array}{l}\text { Banned all outdoor activities, the closure of } \\
\text { cafes and the restriction of the number of } \\
\text { people in outdoor activities to a maximum of } \\
100 \text { persons. }\end{array}$ \\
\hline March 21, 2020 & The second military order was issued. & $\begin{array}{l}\text { Led to the closure of all shopping centers } \\
\text { banning of groups of more than } 3 \text { people in } \\
\text { the streets during daytime and imposed the } \\
\text { curfew from } 10 \text { p.m. to } 6 \text { a.m. }\end{array}$ \\
\hline March 24, 2020 & $\begin{array}{l}\text { The national lockdown law came into } \\
\text { force. }\end{array}$ & $\begin{array}{l}\text { All movements were restricted, except for } \\
\text { work purposes, health needs and essential } \\
\text { activities. }\end{array}$ \\
\hline May 14,2020 & The lockdown ended. & \\
\hline May 15,2020 & The activities were gradually resumed. & \\
\hline July 18,2020 & The quarantine law came into force. & \\
\hline
\end{tabular}

